SYSTEMATIC REVIEW

\title{
Antithrombotic treatment for peripheral arterial disease
}

\author{
Daniel G Hackam, John W Eikelboom
}

Heart 2007;93:303-308. doi: 10.1136/hrt.2006.102350

See end of article for authors' affiliations

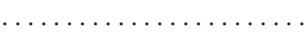

Correspondence to: Dr D G Hackam, Toronto Rehabilitation InstituteCardiac Site, 347 Rumsey Road, Toronto, Ontario, Canada M4G 1R7; Daniel. Hackam@ices.on.ca

Accepted

20 September 2006

Published Online First

11 October 2006
Context: Patients with peripheral arterial disease (PAD) bear a substantial risk for vascular events in the coronary, cerebral and peripheral circulations. In addition, this disorder is associated with a systemic milieu characterised by ongoing platelet activation and heightened thrombogenesis.

Objective: To determine the optimal antithrombotic prophylaxis for patients with PAD.

Data sources: Using terms related to PAD and antithrombotic agents, we searched the following databases for relevant articles: MEDLINE, EMBASE, the Cochrane Central Register of Controlled Trials, the Cochrane Database of Systematic Reviews, the National Institutes of Health Clinical Trials Database, Web of Science, and the International Pharmaceutical Abstracts Database (search dates: 1 January 1990 to 1 January 2007). Additional articles were identified from cardiovascular and vascular surgery conference proceedings, bibliographies of review articles, and personal files.

Study selection: We focused on randomised trials, systematic reviews and consensus guidelines of antithrombotic therapies for PAD.

Data extraction: Detailed study information was abstracted by each author working independently.

Results: Multiple studies show that patients with PAD manifest platelet hyperaggregability, increased levels of soluble platelet activation markers, enhanced thrombin generation and altered fibrinolytic potential. Many of these markers predict subsequent cardiovascular events. Available randomised trials and meta-analyses show that most available antithrombotic agents prevent major cardiovascular events and death in patients with PAD, including aspirin, aspirin/dipyridamole, clopidogrel, ticlopidine, picotamide and oral anticoagulants.

Conclusions: Although the most favourable risk-benefit profile, cost-effectiveness and overall evidence base supports aspirin in this setting, we provide scenarios in which alternatives to aspirin should be considered.
$\mathrm{R}$ ecent estimates suggest that nearly 30 million people are affected by peripheral arterial disease (PAD) in North America and Western Europe. ${ }^{1}$ In older patients, or those with risk factors such as diabetes mellitus or smoking, the prevalence of $\mathrm{PAD}$ approaches $20-30 \% .^{2}$ This disorder is important in several aspects. The local occlusive process underlying PAD worsens progressively in a substantial number of patients (about $25 \%$ in the first 5 years after diagnosis), and such individuals often require vascular intervention despite optimal medical treatment. ${ }^{1}$ A smaller subset progress to major amputation (about 1\%/year). Interventions comprise the largest portion of economic costs in this condition. ${ }^{3}$

Of equal importance, PAD is often associated with atherosclerosis in other vascular areas and patients with the disorder are at markedly increased risk for vascular events and death. ${ }^{4}$ PAD also confers a negative effect on health status and quality of life, similar in degree to disabling angina or heart failure. ${ }^{5}$ Finally, because of shared antecedents, PAD commonly clusters with other major comorbidities, including chronic obstructive lung disease, heart failure, diabetes mellitus, dementia and atrial fibrillation..$^{6-8}$

\section{PAD AND THROMBOGENESIS}

As with other manifestations of atherosclerosis, platelets and clotting factors play a pivotal part in the progression of PAD and the genesis of complications. Many studies have suggested that patients with $\mathrm{PAD}$ manifest platelet hyperaggregability, increased levels of soluble platelet activation markers, enhanced thrombin generation and altered fibrinolytic potential (summarised in table 1). ${ }^{9-23}$ These findings, which are consistent across the different stages of PAD, have important ramifications. Individually, many of the markers characterising the prothrombotic environment of PAD are predictive of future cardiovascular events. ${ }^{24-26}$ Komarov et al, for instance, showed that patients with PAD with a D-dimer concentration in the fifth quintile had a 14-fold greater risk of cardiovascular events than those with a D-dimer in the first quintile, even after adjusting for confounders. ${ }^{25}$ Moreover, such rises correlate strongly with the severity of PAD and predict deterioration of symptoms and physical function. Taken together with the increased cardiovascular risk posed by PAD, these data underline the importance of considering antithrombotic prophylaxis in all such patients.

\section{SELECTION OF ANTITHROMBOTIC TREATMENT}

A variety of antithrombotic agents have been studied in patients with PAD. These include antiplatelet drugs (such as aspirin, thienopyridines and picotamide) and oral anticoagulants, specifically, coumarins (table 2). New evidence is available for many of these approaches, and recent guidelines have added considerable clarity. ${ }^{27-29}$ On the basis of randomised trials and systematic reviews, the various therapeutic options are discussed in detail below, starting with the most widely prescribed agent, aspirin.

\section{TREATMENT OPTIONS}

Aspirin

Acetylsalicylic acid (aspirin) has a large and distinguished evidence base for preventing myocardial infarction and stroke in patients with cardiovascular disease, perhaps best summarised in the Antithrombotic Trialists' Collaboration (ATC) third systematic overview. ${ }^{41}$ This report included 42 randomised trials of antiplatelet treatment in 9214 patients with PAD,

Abbreviations: ATC, Antithrombotic Trialists' Collaboration; OAC, oral anticoagulants; PAD, peripheral arterial disease 
Table 1 Studies on markers of platelet function and coagulation in patients with peripheral arterial disease

\begin{tabular}{|c|c|c|}
\hline Study & Sample & Key findings: PAD $v$ controls \\
\hline Cassar $^{9}$ & $60 \mathrm{PAD} / 40$ controls & Higher P-selectin expression and platelet fibrinogen binding \\
\hline Catalano $^{10}$ & $30 \mathrm{PAD} / 40$ controls & Higher TM levels \\
\hline Cortellaro" & $50 \mathrm{PAD} / 58 \mathrm{CAD}$ or & Higher D-dimer and lower IPA antigen and fibrinolytic capacity; D-dimer and fibrinolytic capacity \\
\hline Devine $^{12}$ & $\begin{array}{l}\text { CVD controls without PAD } \\
29 \mathrm{PAD} / 10 \text { controls }\end{array}$ & $\begin{array}{l}\text { predictive of subsequent vascular events } \\
\text { Higher anti-factor XIII } \alpha \text {-chain binding to platelets }\end{array}$ \\
\hline Gosk-Bierska ${ }^{13}$ & $59 \mathrm{PAD} / 26$ controls & $\begin{array}{l}\text { Higher anti-tactor XIII } \alpha \text {-chain binding to platelets } \\
\text { Higher vWF, fibrinogen, TAT and PF4 }\end{array}$ \\
\hline Gresele $^{14}$ & $63 \mathrm{PAD} / 18$ controls & Higher urinary 11-dehydro-thromboxane B2 levels \\
\hline Handa ${ }^{15}$ & $18 \mathrm{PAD} / 19$ controls & Higher TM, fibrinogen, $\alpha 1$-AT and TAT; lower $\alpha 2$-PI levels \\
\hline Killewich $^{16}$ & $69 \mathrm{PAD} / 11$ controls & Higher PAI- 1 and IPA antigen; lower IPA activity \\
\hline Koksch $^{17}$ & $50 \mathrm{PAD} / 50$ controls & $\begin{array}{l}\text { Higher fibrinogen, vWF, PAl-1, IPA, P-selectin on both stimulated and non-stimulated platelets; } \\
\text { lower PAl-1/tPA ratio }\end{array}$ \\
\hline Lowe $^{18}$ & $388 \mathrm{PAD} / 1581$ controls & $\begin{array}{l}\text { Higher blood viscosity, hematocrit, fibrinogen, leucocyte elastase, and uric acid; haematocrit and } \\
\text { viscosity directly correlated with PAD severity }\end{array}$ \\
\hline Makin $^{19}$ & $234 \mathrm{PAD} / 50$ controls & Higher soluble P-selectin, vWF, TF and fibrinogen; fibrinogen directly correlated with PAD severity \\
\hline McDermott ${ }^{20}$ & $346 \mathrm{PAD} / 203$ controls & D-dimer and hsCRP inversely correlated with limb function in both PAD and controls \\
\hline Reininger $^{21}$ & 92 PAD/70 controls & Higher platelet adhesion and aggregation, fibrinogen, fibrin monomer, $\mathrm{d}$-dimer and TAT \\
\hline Robless ${ }^{22}$ & $20 \mathrm{PAD} / 20$ controls & Higher spontaneous and induced platelet aggregation \\
\hline Zeiger $^{23}$ & $50 \mathrm{PAD} / 50$ controls & Higher P-selectin expression on platelets, platelet aggregates and platelet-derived microparticles \\
\hline
\end{tabular}

$\alpha 1$-AT, $\alpha$ 1-antitrypsin; $\alpha 2$-PI, $\alpha$ 2-plasmin inhibitor; CAD, cardiovascular disease; CVD, cerebrovascular disease; hsCRP, highly sensitive C reactive protein; PAl-1, plasminogen activator inhibitor 1; PF4, platelet factor 4; TAT, thrombin-antithrombin complex; TM, thrombomodulin; $\mathrm{PAA}$, tissue plasminogen activator; vWF, von Willebrand Factor.

including trials in intermittent claudication $(\mathrm{n}=26)$, peripheral bypass grafting $(n=12)$ and peripheral angioplasty $(n=4)$. The pooled odds reduction in major cardiovascular events for antiplatelet treatment in patients with PAD was $23 \%$ $(\mathrm{p}=0.001)$, similar to the aggregate finding for all 195 trials included in the meta-analysis (odds reduction $22 \%, \mathrm{p}<0.001$ ). This robust evidence has often been cited to support aspirin treatment in patients with PAD, but careful examination of the individual trials shows that nearly $60 \%$ of the data relate to other antiplatelet agents. Thus the efficacy of aspirin in PAD must be extrapolated from other treatment trials in the ATC database. This does not necessarily mean that aspirin is ineffective in patients with PAD; indeed, the benefit of aspirin on cardiovascular events has been confirmed in a number of other high-risk settings as well as in primary prevention. ${ }^{42}$

More recently, Collins et al ${ }^{43}$ reported a meta-analysis of aspirin and other antithrombotic agents after infrainguinal bypass graft. Of the 10 included trials, 7 compared antiplatelet agents with placebo and 3 compared oral anticoagulants with placebo. Six of the 7 antiplatelet trials studied aspirin or aspirin/ dipyridamole. Antiplatelet treatment reduced the odds of graft occlusion by $57 \%$ (95\% confidence interval (CI) 33 to 73 ), which was similar to the overall effect across all 10 trials (odds reduction 54\%, 95\% CI 34 to 68 ). Mortality was also significantly reduced (odds ratio (OR) $0.7,95 \%$ CI 0.51 to 0.95 ). These benefits were accompanied by a non-significant

Table 2 Major randomised controlled trials of antithrombotic treatment in peripheral arterial disease

\begin{tabular}{|c|c|c|c|}
\hline Study & Comparison & Patients & Efficacy for cardiovascular events \\
\hline \multicolumn{4}{|l|}{ Aspirin } \\
\hline MATCH $^{30}$ & $\begin{array}{l}\text { ASA + clopidogrel } v \\
\text { clopidogrel }\end{array}$ & $\begin{array}{l}7599 \text { patients with stroke or TIA including } \\
776 \text { with PAD }\end{array}$ & $\begin{array}{l}\text { Overall } 6 \% \text { reduction favouring dual treatment }(p=0.24) \text {; } \\
20 \% \text { reduction in PAD subgroup }(p=N S)\end{array}$ \\
\hline McCollum $^{31}$ & $\begin{array}{l}\text { ASA + dipyridamole } v \\
\text { placebo }\end{array}$ & $\begin{array}{l}549 \text { patients undergoing femoralpopliteal } \\
\text { bypass }\end{array}$ & $45 \%$ reduction favouring ASA + dipyridamole $(p=0.004)$ \\
\hline \multicolumn{4}{|l|}{ Thienopyridines } \\
\hline CAPRIE $^{32}$ & Clopidogrel $v$ ASA & $\begin{array}{l}19185 \text { with atherosclerosis including } 6452 \\
\text { with PAD }\end{array}$ & $\begin{array}{l}\text { Overall } 9 \% \text { reduction favouring clopidogrel }(p=0.043) \\
24 \% \text { reduction in PAD subgroup }(p=0.003)\end{array}$ \\
\hline CHARISMA $^{33}$ & Clopidogrel + ASA v ASA & $\begin{array}{l}15603 \text { with atherosclerosis including } 2838 \\
\text { with PAD }\end{array}$ & $\begin{array}{l}\text { Overall } 7 \% \text { reduction favouring clopidogrel }(p=0.22) \text {; } \\
13 \% \text { reduction in PAD subgroup }(p=0.29)\end{array}$ \\
\hline CREDO $^{34}$ & Clopidogrel + ASA v ASA & $\begin{array}{l}2116 \text { patients including } 272 \text { with PAD or } \\
\text { CVD }\end{array}$ & $\begin{array}{l}\text { Overall } 27 \% \text { reduction favouring clopidogrel }(p=0.02) \\
48 \% \text { reduction in PAD/CVD subgroup }(p=0.06)\end{array}$ \\
\hline EMATAP $^{35}$ & Ticlopidine $v$ placebo & 615 patients with claudication & $74 \%$ reduction favouring ticlodipine $(p=0.002)$ \\
\hline $\mathrm{STIMS}^{36}$ & Ticlopidine $v$ placebo & 687 patients with claudication & $\begin{array}{l}\text { Non-significant } 11 \% \text { reduction favouring ticlopidine }(p=0.24) \\
29 \% \text { reduction in all-cause mortality }(p=0.015)\end{array}$ \\
\hline \multicolumn{4}{|c|}{ Thromboxane inhibitors } \\
\hline $\mathrm{ADEP}^{37}$ & Picotamide $v$ placebo & 2304 patients with claudication & Non-significant $19 \%$ reduction favouring picotamide $(p=0.056)$ \\
\hline DAVID ${ }^{38}$ & Picotamide $v$ ASA & 1209 patients with claudication and diabetes & $\begin{array}{l}\text { Non-significant } 18 \% \text { reduction favouring picotamide }(p=0.30) \\
45 \% \text { reduction in all-cause mortality }(p=0.047)\end{array}$ \\
\hline \multicolumn{4}{|r|}{ 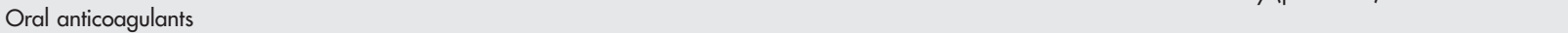 } \\
\hline Dutch $\mathrm{BOA}^{39}$ & Coumarins* $v$ ASA & $\begin{array}{l}2690 \text { patients undergoing infrainguinal } \\
\text { grafting }\end{array}$ & Non-significant $11 \%$ reduction favouring coumarins $(p=0.19)$ \\
\hline WAVE $^{40}$ & Warfarin + ASA v ASA & $\begin{array}{l}2181 \text { patients with symptomatic or } \\
\text { asymptomatic PAD }\end{array}$ & Non-significant $8 \%$ reduction favouring warfarin + ASA $(p=0.49)$ \\
\hline \multicolumn{4}{|c|}{$\begin{array}{l}\text { ADEP, atherosclerotic disease evolution by picotamide; ASA, acetylsalicylic acid; CAPRIE, Clopidogrel versus Aspirin in Patients at Risk of Ischaemic Events; CHARISMA, } \\
\text { Clopidogrel for High Atherothrombotic Risk and Ischemic Stabilization, Management and Avoidance; CREDO, Clopidogrel for the Reduction of Events During } \\
\text { Observation; CVD, cerebrovascular disease; DAVID, Drug evaluation in Atherosclerotic Vascular disease In Diabetics; Dutch BOA, Dutch Bypass Oral Anticoagulants or } \\
\text { aspirin; EMATAP, Estudio Multicentrico Argentino de la Ticlopidine en las Arteriopatias Perifericas; MATCH, Management of Atherothrombosis with Clopidogrel in } \\
\text { High-risk patients; NS, not significant; PAD, peripheral arterial disease; STIMS, Swedish Ticlopidine Multicentre Study; TIA, transient ischaemic attack; WAVE, Warfarin } \\
\text { Antiplatelet Vascular Evaluation. } \\
\text { *Phenprocoumon or acenocoumarol. }\end{array}$} \\
\hline
\end{tabular}


Table 3 Characteristics of various antithrombotic treatments

\begin{tabular}{|c|c|c|}
\hline Treatment & Advantages & Disadvantages \\
\hline Aspirin & $\begin{array}{l}\text { Large evidence base for prevention of vascular events } \\
\text { Excellent cost effectiveness }\end{array}$ & $\begin{array}{l}\text { Gastrointestinal intolerance, bleeding and allergy } \\
\text { Efficacy in several comparative trials was inferior to other agents }\end{array}$ \\
\hline Clopidogrel & Efficacy in patients with coexisting CAD & Less cost effective than aspirin \\
\hline & Marginal benefit over aspirin possibly amplified in PAD & Evidence in PAD is limited to subgroup analyses \\
\hline Picotamide & $\begin{array}{l}\text { Enhanced efficacy in PAD with concomitant diabetes } \\
\text { Favourable effects on claudication symptoms }\end{array}$ & $\begin{array}{l}\text { Inconvenient dosing schedule (twice daily) } \\
\text { Unavailable in many settings }\end{array}$ \\
\hline Ticlopidine & $\begin{array}{l}\text { Established efficacy in patients with PAD } \\
\text { Favourable effects on claudication symptoms }\end{array}$ & $\begin{array}{l}\text { Haematological toxicity significantly greater than clopidogrel } \\
\text { Inconvenient dosing schedule (twice daily) }\end{array}$ \\
\hline Coumarins & $\begin{array}{l}\text { Reduced graft occlusion after revascularisation } \\
\text { Coexisting indications (eg, atrial fibrillation, deep vein thrombosis, } \\
\text { mechanical heart valves) }\end{array}$ & $\begin{array}{l}\text { Efficacy in PAD is not superior to antiplatelet treatment } \\
\text { Higher rates of serious haemorrhage than antiplatelet treatment } \\
\text { Complexity of treatment and requirement for monitoring }\end{array}$ \\
\hline
\end{tabular}

trend towards increased bleeding (OR 1.82, 95\% CI 0.43 to 7.73 ). Given the predominance of aspirin trials in this analysis, these data support aspirin-based prophylaxis in patients with PAD.

Additional advantages of aspirin are its affordability (about US $\$ 0.04 /$ dose), wide availability, ease of dosing and lack of necessity for therapeutic monitoring. The main disadvantages are gastrointestinal intolerance in a substantial number of patients and, more importantly, the high residual risk of cardiovascular events despite long-term treatment. The latter has spurred the investigation of other antithrombotic approaches for patients with PAD (and indeed other forms of atherosclerosis). The most common non-aspirin antiplatelets studied in this setting have been ticlopidine, clopidogrel and picotamide. An additional rationale for investigating these drugs is that they inhibit disparate mechanisms of platelet activation and may thus provide complementary antiplatelet activity.

\section{Thienopyridines}

Ticlopidine and clopidogrel are members of the thienopyridine class of antiplatelet agents, which act by blocking the adenosine diphosphate-mediated pathway of platelet activation. A metaanalysis of ticlopidine treatment in patients with intermittent claudication suggested a significant benefit on mortality (OR $0.68,95 \%$ CI 0.49 to 0.95 ) and need for revascularisation (OR $0.62,95 \%$ CI 0.41 to 0.93$).{ }^{44}$ Another meta-analysis in patients undergoing lower limb procedures for PAD showed a substantial reduction in postoperative reocclusion favouring active treatment (OR $0.53,95 \%$ CI 0.33 to 0.85 ) and a near-significant reduction in amputation (OR $0.29,95 \%$ CI 0.08 to 1.01 ). ${ }^{45}$ On the other hand, no adequately powered randomised trial has compared ticlopidine with other effective antiplatelets in patients with PAD, and ticlopidine has largely been supplanted by clopidogrel due to the risk of life-threatening neutropenia with ticlopidine.

Some evidence suggests that the presence of PAD may identify a subset of patients more likely to benefit from clopidogrel treatment. For example, in the Clopidogrel versus Aspirin in Patients at Risk of Ischemic Events trial, clopidogrel reduced the risk of cardiovascular events by $9 \%$ in comparison with aspirin (95\% CI 0.3 to $17 ; \mathrm{p}=0.043) .^{32}$ However, among the 6452 patients enrolled on the basis of PAD the risk reduction was nearly three times greater $(24 \%$; $95 \%$ CI 9 to 36 ; $\mathrm{p}=0.003)$ and a formal test of interaction for this subgroup effect was significant $(p=0.042)$.

Similar findings of incremental benefit were noted in the Clopidogrel for the Reduction of Events During Observation study, in which clopidogrel plus aspirin was compared with aspirin alone in patients with coronary artery disease scheduled for percutaneous intervention. ${ }^{34}$ Patients with concomitant extracoronary vascular disease (defined as peripheral or cerebrovascular atherosclerosis) had a $>2$-fold greater risk reduction for the primary end point compared with patients who did not have extracoronary vascular disease (OR 48\%, 95\% CI -4 to $74, v$ OR $18 \%, 95 \%$ CI -11 to 40 , respectively). In addition, the incidence of major cardiovascular events (death, myocardial infraction, stroke or urgent revascularisation) was significantly reduced, from $19.6 \%$ to $9.2 \%$, in patients with extracoronary vascular disease $(p=0.02$, absolute risk reduction $10.4 \%$ ). A similar trend for increased benefit by presence of PAD was found in the Management of Atherothrombosis with Clopidogrel in High-risk Patients (MATCH) study. ${ }^{30}$ However, in the most recent study of long-term clopidogrel for the prevention of atherothrombosis (CHARISMA: Clopidogrel for High Atherothrombotic Risk and Ischemic Stabilization, Management and Avoidance), there was no benefit for clopidogrel on cardiovascular events either overall (RR 0.93, $95 \%$ CI 0.83 to 1.05$)$ or among the 3531 patients enrolled with PAD (RR 0.87, 95\% CI 0.67 to 1.13 ). ${ }^{33}$

\section{Thromboxane antagonists}

Picotamide is an agent with inhibitory effects on thromboxane A2 synthase and thromboxane A2/prostaglandin endoperoxide $\mathrm{H} 2$ receptors on platelets. Three small, early randomised trials suggested that picotamide lowers the risk of cardiovascular events in patients with acute myocardial infarction, previous ischaemic stroke or diabetes. ${ }^{46-48}$ Two larger randomised studies studied the efficacy of picotamide in patients with PAD, against either placebo ${ }^{37}$ or aspirin. ${ }^{38}$ In the placebo-controlled study, picotamide did not reduce the risk of cardiovascular events in the intention-to-treat analysis (OR $0.80,95 \%$ CI 0.63 to 1.01 ; $\mathrm{p}=0.057$ ), although a suggestion of benefit was found in the on-treatment analysis (OR 0.76, 95\% CI 0.59 to 0.97 ; $\mathrm{p}=0.029) .{ }^{37} \mathrm{~A}$ more substantial reduction was found in a small subgroup of patients with both PAD and diabetes (OR 0.52 , $95 \%$ CI 0.24 to $0.74 ; \mathrm{p}=0.022$ ), but this analysis was conducted and reported retrospectively. ${ }^{49}$

Building on the latter finding, a subsequent randomised study compared picotamide with aspirin specifically in patients with PAD and diabetes. ${ }^{38}$ The primary end point, all-cause mortality, was reduced by $45 \%$ in patients allocated to picotamide (95\% CI 2 to $69 ; \mathrm{p}=0.047$ ). However, the principal secondary end point of total morbidity and mortality (comprising myocardial infarction, stroke, major amputation and death) was not reduced $(\mathrm{p}=0.3)$. Of additional concern, morbidity and mortality data were unavailable for $18 \%$ and $5 \%$ of patients, respectively. Further hampering the applicability of these findings, picotamide is currently unavailable in many countries.

\section{Oral anticoagulants}

Updating previous evidence, Anand et al recently reported a meta-analysis of nine randomised trials of oral anticoagulants (OAC) involving 4889 patients..$^{50}$ Compared with control (no treatment), OAC reduced the risk of graft occlusion by $37 \%$ 


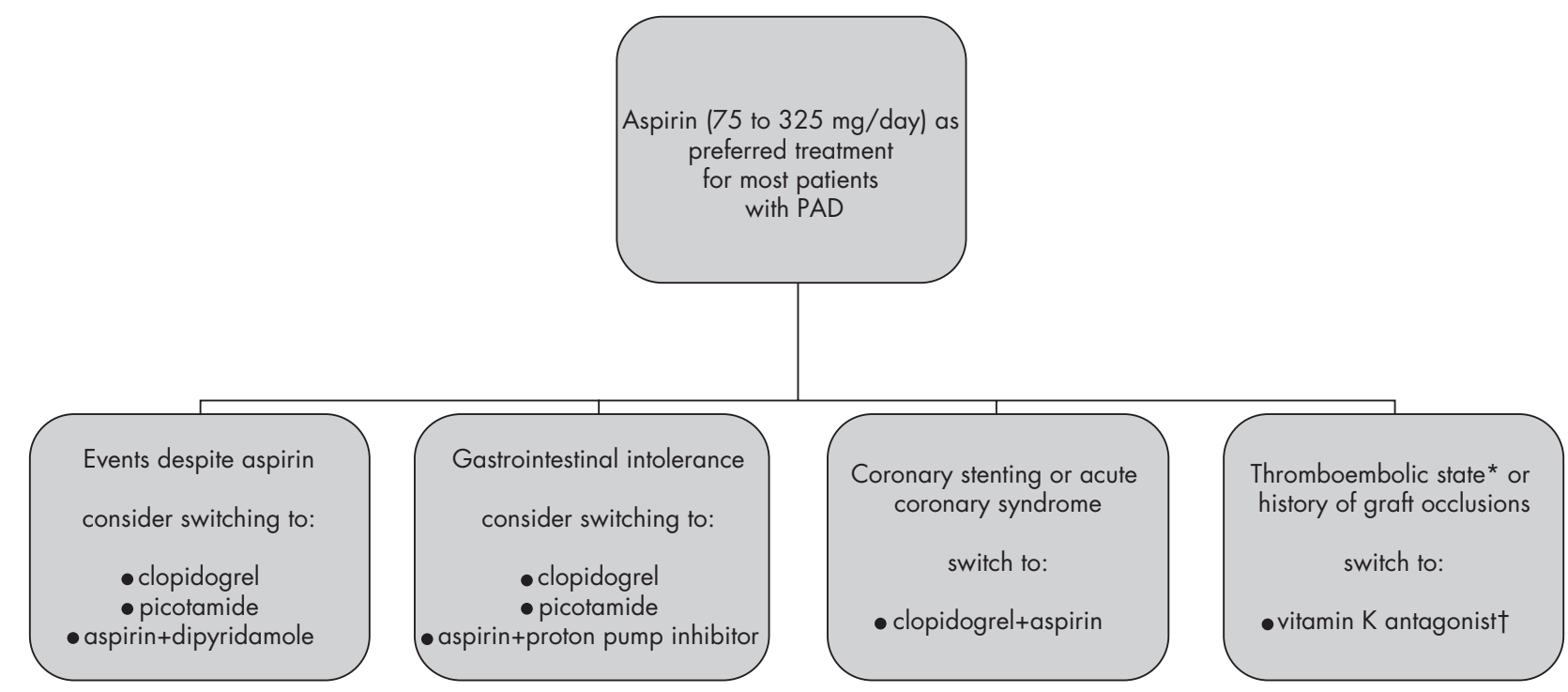

Figure 1 Selection of antithrombotic treatment in patients with peripheral arterial disease. *Atrial fibrillation, mechanical heart valve, underlying thrombophilia, or venous thromboembolism. †Oral coumarin plus aspirin in patients with mechanical heart valves. PAD, peripheral arterial disease.

(95\% CI 11 to 56) with a trend towards decreased mortality (OR $0.73,95 \%$ CI 0.5 to 1.07$)$. The risk of major haemorrhage was substantially higher among OAC-allocated patients (OR 3.64, $95 \%$ CI 2.03 to 6.56 ). When compared with aspirin, OAC was not more effective in preventing graft occlusion or death (OR 0.91 , $95 \%$ CI 0.77 to 1.06; and OR 1.04 , 95\% CI 0.85 to 1.29 , respectively); moreover, the risk of major haemorrhage was nearly doubled $(1.96,95 \%$ CI 1.43 to 2.69$)$. Finally, the combination of OAC plus aspirin was not more effective than aspirin alone, with higher rates of mortality and major haemorrhage (OR 1.57, 95\% CI 1.16 to 2.12; and OR 2.13, $95 \%$ CI 1.27 to 3.57 , respectively) and no reduction in graft loss (OR $0.84,95 \%$ CI 0.62 to 1.12 ).

Since this meta-analysis, a large randomised trial $(n=2161)$ comparing the combination of moderate intensity warfarin treatment (median INR 2.2) and aspirin with aspirin alone has been completed. ${ }^{40}$ There was no difference between the two arms in the primary end point of cardiovascular death, myocardial infarction or stroke (RR 0.92, 95\% CI 0.73 to 1.16). On the other hand, life-threatening bleeding (defined as bleeding that was fatal, intracranial or required surgical intervention or the transfusion of at least 4 units of blood products) was increased by more than threefold (RR 3.41; 95\% CI 1.84 to 6.35 ) and haemorrhagic stroke by more than 15 -fold (RR 15.2, 95\% CI 2 to 115.6). Together these data suggest that oral anticoagulants should not be preferred to antiplatelet agents for the routine treatment of PAD; additional disadvantages include the inconvenience of treatment, poor adherence, potential for drug and food interactions, and the requirement for laboratory monitoring and dose titration.

\section{RECOMMENDATIONS AND SUMMARY}

In terms of affordability, safety and efficacy, aspirin remains the first-line agent for most patients with PAD (table 3). However, there are a number of scenarios in which other agents might be considered (fig 1). For example, patients who experience vascular events while on aspirin should probably be switched to clopidogrel or picotamide. Patients with a history of stroke might particularly benefit from dual treatment with aspirin and dipyridamole, as suggested by the recent European/Australasian Stroke Prevention in Reversible Ischaemia trial, the favourable results of which are in line with previous randomised trials in PAD. ${ }^{31}{ }^{51}$ Gastrointestinal intolerance to non-steroidal anti-inflammatory agents may be another reason to select clopidogrel or picotamide, although a reasonable and proved option would be to combine aspirin with a proton pump inhibitor. ${ }^{52}$ Patients with PAD who undergo coronary stenting or who have acute coronary syndrome should be prescribed dual treatment with clopidogrel and aspirin, on the basis of strong efficacy in randomised trials. ${ }^{53}$ Finally, moderate intensity warfarin treatment (target international normalised ratio 2.5) would be acceptable in the presence of coexisting indications such as atrial fibrillation or recent venous thrombosis, although it might also be considered for patients with a history of peripheral graft occlusion. ${ }^{29}$

Although chronic antithrombotic prophylaxis should be prescribed to nearly all patients with PAD, many studies suggest widespread underutilisation of this efficacious strategy, with treatment gaps ranging from $25 \%$ to $>50 \% .^{54-57}$ In addition to increased use, other approaches are needed to combat the risk of cardiovascular events posed by this disease. Randomised trials have supported the efficacy of statins and antihypertensive agents for preventing vascular events in individuals affected by PAD. ${ }^{58} 59$ These approaches should be coupled with intensive lifestyle modification, including structured exercise, prudent diet and smoking cessation. Recent cohort studies have suggested remarkable efficacy from combining these strategies in patients with $\mathrm{PAD}$, suggesting that far from being fatalistic, doctors encountering PAD should be optimistic that they possess effective tools for comprehensively managing this condition..$^{6061}$

\section{Authors' affiliations}

Daniel G Hackam, Division of Clinical Pharmacology and Toxicology, University of Toronto, Toronto, Canada John W Eikelboom, Division of Hematology, McMaster University, Hamilton, Canada

Funding: DGH is supported by the Canadian Institutes for Health Research and the Clinician Scientist Training Program of the University of Toronto. JWE is supported by a Tier II Canada Chair in Cardiovascular Medicine, Canadian Institutes for Health Research. The funding sponsors had no role in the conception of the article, the literature review and synthesis, or the decision to submit for publication.

Competing interests: None for DGH. JWE has received research funding from Bayer and Sanofi-Aventis. 


\section{REFERENCES}

1 The TransAtlantic Inter-Society Consensus (TASC) Group. Management of peripheral arterial disease (PAD). Eur J Vasc Endovasc Surg 2000;19(Suppl A):S1-S250.

2 Hirsch AT, Criqui MH, Treat-Jacobson D, et al. Peripheral arterial disease detection, awareness, and treatment in primary care. JAMA 2001;286:1317-24.

3 Holler D, Claes C, von der Schulenburg JM. Treatment costs and quality of life of patients with peripheral arterial occlusive disease-the German perspective. Vasa 2004;33:145-53.

4 Criqui MH, Langer RD, Fronek A, et al. Mortality over a period of 10 years in patients with peripheral arterial disease. N Engl J Med 1992;326:381-6.

5 Dumville JC, Lee AJ, Smith FB, et al. The health-related quality of life of people with peripheral arterial disease in the community: the Edinburgh Artery Study. Br J Gen Pract 2004;54:826-31.

6 Pedersen G, Laxdal E, Hagala M, et al. The impact of comorbidity on long-term results of above-knee prosthetic femoropopliteal bypass for intermittent claudication. Int Angiol 2005;24:245-9.

7 Newman AB, Fitzpatrick AL, Lopez O, et al. Dementia and Alzheimer's disease incidence in relationship to cardiovascular disease in the Cardiovascular Health Study cohort. J Am Geriatr Soc 2005;53:1101-7.

8 Conway DS, Lip GY. Comparison of outcomes of patients with symptomatic peripheral artery disease with and without atrial fibrillation (the West Birmingham Atrial Fibrillation Project). Am J Cardiol. 2004;93: 1422-5, A10)

9 Cassar K, Bachoo P, Ford I, et al. Platelet activation is increased in peripheral arterial disease. J Vasc Surg 2003;38:99-103.

10 Catalano M, Russo U, Libretti A. Plasma beta-thromboglobulin levels and claudication degrees in patients with peripheral vascular disease. Angiology 1986;37:339-42

11 Cortellaro M, Cofrancesco E, Boschetti C, et al. Association of increased fibrin turnover and defective fibrinolytic capacity with leg atherosclerosis. The PLAT Group. Thromb Haemost 1994;72:292-6.

12 Devine DV, Andestad G, Nugent D, et al. Platelet-associated factor XIII as a marker of platelet activation in patients with peripheral vascular disease. Arterioscler Thromb 1993;13:857-62.

13 Gosk-Bierska I, Adamiec R, Alexewicz P, et al. Coagulation in diabetic and nondiabetic claudicants. Int Angiol 2002;21:128-33.

14 Gresele P, Catalano M, Giammarresi C, et al. Platelet activation markers in patients with peripheral arterial disease-a prospective comparison of different platelet function tests. Thromb Haemost 1997;78:1434-7.

15 Handa K, Takao M, Nomoto J, et al. Evaluation of the coagulation and fibrinolytic systems in men with intermittent claudication. Angiology 1996;47:543-8

16 Killewich LA, Gardner AW, Macko RF, et al. Progressive intermittent claudication is associated with impaired fibrinolysis. J Vasc Surg 1998;27:645-50.

17 Koksch M, Zeiger F, Wittig K, et al. Coagulation, fibrinolysis and platelet Pselectin expression in peripheral vascular disease. Eur J Vasc Endovasc Surg 2001;21:147-54

18 Lowe GD, Fowkes FG, Dawes J, et al. Blood viscosity, fibrinogen, and activation of coagulation and leukocytes in peripheral arterial disease and the normal population in the Edinburgh Artery Study. Circulation 1993;87:1915-20.

19 Makin AJ, Chung NA, Silverman SH, et al. Thrombogenesis and endothelia damage/dysfunction in peripheral artery disease. Relationship to ethnicity and disease severity. Thromb Res 2003;111:221-6.

20 McDermott MM, Guralnik JM, Greenland P, et al. Inflammatory and thrombotic blood markers and walking-related disability in men and women with and without peripheral arterial disease. J Am Geriatr Soc 2004;52:1888-94.

21 Reininger CB, Graf J, Reininger AJ, et al. Increased platelet and coagulatory activity indicate ongoing thrombogenesis in peripheral arterial disease. Thromb Res 1996;82:523-32.

22 Robless PA, Okonko D, Lintott $P$, et al. Increased platelet aggregation and activation in peripheral arterial disease. Eur J Vasc Endovasc Surg 2003;25:16-22.

23 Zeiger F, Stephan S, Hoheisel G, et al. P-Selectin expression, platelet aggregates, and platelet-derived microparticle formation are increased in peripheral arterial disease. Blood Coagul Fibrinolysis 2000;11:723-8.

24 Danesh J, Lewington S, Thompson SG, et al. Plasma fibrinogen level and the risk of major cardiovascular diseases and nonvascular mortality: an individual participant meta-analysis. JAMA 2005;294:1799-809.

25 Komarov A, Panchenko E, Dobrovolsky A, et al. D-dimer and platelet aggregability are related to thrombotic events in patients with peripheral arterial occlusive disease. Eur Heart J 2002;23:1309-16.

26 Musicant SE, Taylor J, Peters D, et al. Prospective evaluation of the relationship between $\mathrm{C}$-reactive protein, $\mathrm{D}$-dimer and progression of peripheral arterial disease. J Vas Surg 2006;43:772-80.

27 ACC/AHA 2005 Practice Guidelines for the Management of Patients With Peripheral Arterial Disease (Lower Extremity, Renal, Mesenteric, and Abdominal Aortic): A Collaborative Report from the American Association for Vascular Surgery/Society for Vascular Surgery, ${ }^{\star}$ Society for Cardiovascular Angiography and Interventions, Society for Vascular Medicine and Biology, Society of Interventional Radiology, and the ACC/AHA Task Force on Practice Guidelines (Writing Committee to Develop Guidelines for the Management of Patients With Peripheral Arterial Disease): Endorsed by the American Association of Cardiovascular and Pulmonary Rehabilitation; National Heart, Lung, and Blood Institute; Society for Vascular Nursing; TransAtlantic Inter-Society Consensus; and Vascular Disease Foundation. Circulation 2006;113:e463-e654.
28 Abramson BL, Huckell V, Anand S, et al. Canadian Cardiovascular Society Consensus Conference: peripheral arterial disease-executive summary. Can J Cardiol 2005;21:997-1006.

29 Clagett GP, Sobel M, Jackson MR, et al. Antithrombotic therapy in peripheral arterial occlusive disease: the seventh ACCP conference on antithrombotic and thrombolytic therapy. Chest 2004; 126(Suppl):609S-626.

30 Diener HC, Bogousslavsky J, Brass LM, et al. Aspirin and clopidogrel compared with clopidogrel alone after recent ischaemic stroke or transient ischaemic attack in high-risk patients (MATCH): randomised, double-blind, placebo-controlled trial. Lancet 2004;364:331-7.

31 McCollum C, Alexander C, Kenchington G, et al. Antiplatelet drugs in femoropopliteal vein bypasses: a multicenter trial. J Vasc Surg 1991;13:150-61.

32 CAPRIE Steering Committee. A randomised, blinded, trial of clopidogrel versus aspirin in patients at risk of ischaemic events (CAPRIE). Lancet 1996;348:1329-39.

33 Bhatt DL, Fox KAA, Hacke W, et al. Clopidogrel and aspirin versus aspirin alone for the prevention of atherothrombotic events. N Engl J Med. 2006; doi: 10, 1056/NEJMoa060989.

34 Mukheriee D, Topol EJ, Moliterno DJ, et al. Extracardiac vascular disease and effectiveness of sustained clopidogrel treatment. Heart 2006:92:49-51.

35 Blanchard J, Carreras LO, Kindermans M. Results of EMATAP: a double-blind placebo-controlled multicentre trial of ticlopidine in patients with peripheral arterial disease. Nouv Rev Fr Hematol 1994;35:523-8.

36 Janzon L, Bergqvist D, Boberg J, et al. Prevention of myocardial infarction and stroke in patients with intermittent claudication; effects of ticlopidine. Results from STIMS, the Swedish Ticlopidine Multicentre Study. J Intern Med 1990;227:301-8

37 Balsano F, Violi F. Effect of picotamide on the clinical progression of peripheral vascular disease. A double-blind placebo-controlled study. The ADEP Group. Circulation 1993;87:1563-9.

38 Neri Serneri GG, Coccheri S, Marubini E, et al. Picotamide, a combined inhibitor of thromboxane A2 synthase and receptor, reduces 2-year mortality in diabetics with peripheral arterial disease: the DAVID study. Eur Heart $J$ 2004;25: 1845-52.

39 Tangelder MJ, McDonnel J, Van Busschbach JJ, et al. Quality of life after infrainguinal bypass grafting surgery. Dutch Bypass Oral Anticoagulants or Aspirin (BOA) Study Group. J Vasc Surg 1999;29:913-19.

40 Anand S. Warfarin Antiplatelet Vascular Evaluation : a randomized controlled trial testing moderate intensity oral anticoagulation and antiplatelets therapy vs antiplatelet therapy alone in patients with peripheral arterial disease. World Congress of Cardiology. Hotline Session II; Barcelona, Spain 2006. (WAVE), (WAVE).

41 Collaboration AT. Collaborative meta-analysis of randomised trials of antiplatelet therapy for prevention of death, myocardial infarction, and stroke in high risk patients. BMJ 2002;324:71-86.

42 Berger JS, Roncaglioni MC, Avanzini F, et al. Aspirin for the primary prevention of cardiovascular events in women and men: a sex-specific meta-analysis of randomized controlled trials. JAMA 2006;295:306-13.

43 Collins TC, Souchek J, Beyth RJ. Benefits of antithrombotic therapy after infrainguinal bypass grafting: a meta-analysis. Am J Med 2004; 1 17:93-9.

44 Girolami B, Bernardi E, Prins MH, et al. Antithrombotic drugs in the primary medical management of intermittent claudication: a meta-analysis. Thromb Haemost 1999:81:715-22.

45 Girolami B, Bernardi E, Prins MH, et al. Antiplatelet therapy and other interventions after revascularisation procedures in patients with peripheral arterial disease: a meta-analysis. Eur J Vasc Endovasc Surg 2000;19:370-80.

46 Vetrano A, Milani M, Corsini G. Effects of aspirin or picotamide, an antithromboxane agent, in combination with low-intensity oral anticoagulation in patients with acute myocardial infarction: a controlled randomized pilot trial. G Ital Cardiol 1999:29:524-8.

47 Coto V, Oliviero U, Cocozza M, et al. Long-term safety and efficacy of picotamide, a dual-action antithromboxane agent, in diabetic patients with carotid atherosclerosis: a 6-year follow-up study. J Int Med Res 1998;26:200-5.

48 de Falco FA, Montariello A, Mastroroberto G, et al. Clinical efficacy of picotamide. Clin Ter 1991:138:21-6.

49 Milani M, Longoni A, Maderna M. Effects of picotamide, an antiplatelet agent, on cardiovascular, events in 438 claudicant patients with diabetes: a retrospective analysis of the ADEP study. Br J Clin Pharmacol 1996;42:782-5.

50 The effects of oral anticoagulants in patients with peripheral arterial disease: rationale, design, and baseline characteristics of the Warfarin and Antiplatelet Vascular Evaluation (WAVE) trial, including a meta-analysis of trials. Am Heart J 2006;151:1-9.

51 Halkes PH, van GJ, Kappelle $\amalg$, et al. Aspirin plus dipyridamole versus aspirin alone after cerebral ischaemia of arterial origin (ESPRIT): randomised controlled trial. Lancet 2006;367:1665-73.

52 Chan FKL, Ching JYL, Hung LCT, et al. Clopidogrel versus aspirin and esomeprazole to prevent recurrent ulcer bleeding. N Engl J Med 2005;352:238-44.

53 Steinhubl SR, Berger PB, Mann III JT, et al. Early and sustained dual oral antiplatelet therapy following percutaneous coronary intervention: a randomized controlled trial. JAMA 2002;288:2411-20.

54 Conte MS, Bandyk DF, Clowes AW, et al. Risk factors, medical therapies and perioperative events in limb salvage surgery: observations from the PREVENT II multicenter trial. J Vasc Surg 2005;42:456-64.

55 Okaa RK, Umoh E, Szuba A, et al. Suboptimal intensity of risk factor modification in PAD. Vasc Med 2005; 10:91-6.

56 Lange S, Diehm C, Darius $H$, et al. High prevalence of peripheral arterial disease and low treatment rates in elderly primary care patients with diabetes. Exp Clin Endocrinol Diabetes 2004;112:566-73. 
57 Anand SS, Kundi A, Eikelboom J, et al. Low rates of preventive practices in patients with peripheral vascular disease. Can J Cardiol 1999;15:1259-63.

58 Heart Protection Study Investigators. MRC/BHF Heart Protection Study of cholesterol lowering with simvastatin in 20,536 high-risk individuals: a randomised placebo-controlled trial. Lancet 2002;360:7-22.

59 Ostergren J, Sleight P, Dagenais $G$, et al. Impact of ramipril in patients with evidence of clinical or subclinical peripheral arterial disease. Eur Heart $J$ 2004;25:17-24.
60 Feringa $\mathrm{HHH}$, van Waning VH, Bax JJ, et al. Cardioprotective medication is associated with improved survival in patients with peripheral arterial disease. $J$ Am College Cardiol 2006;47:1182-7.

61 Mukheriee D, Lingam P, Chetcuti S, et al. Missed opportunities to treat atherosclerosis in patients undergoing peripheral vascular interventions: insights from the University of Michigan Peripheral Vascular Disease Quality Improvement Initiative (PVD-QI2). Circulation 2002; 106 1909-12.

\section{IMAGES IN CARDIOLOGY}

\section{Angina during upper limb exercise: pathognomonic clinical feature of coronary-subclavian steal syndrome?}

A 62-year-old patient, with a history of myocardial revascularisation consisting of a left internal mammary artery (LIMA) to the left anterior descending coronary artery (LAD) for significant coronary artery disease 16 years ago, was admitted with intermittent chest pain occurring only during physical activity of the left arm. The stress ECG up to $175 \mathrm{~W}$ was negative for ischaemic signs. His blood pressure was 120/70 $\mathrm{mm} \mathrm{Hg}$ in the right arm and 60/ $40 \mathrm{~mm} \mathrm{Hg}$ in the left arm. Non-invasive evaluation by magnetic resonance tomography (Angio-Surf) demonstrated a complete occlusion (panel A) of the left subclavian artery (LSA), which was confirmed by aortography (panel B). Selective injection of a contrast agent into the left main coronary artery revealed coronary-subclavian steal syndrome (CSSS) demonstrated by reverse

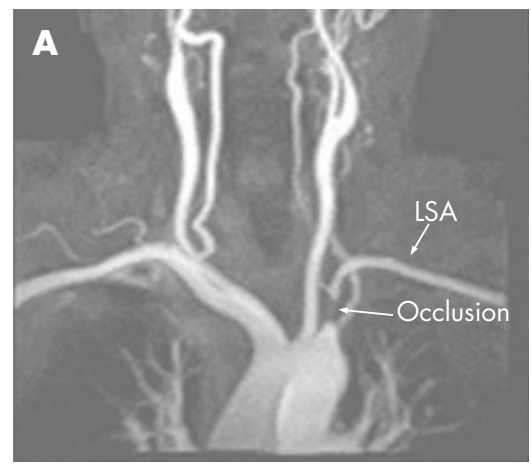

flow from the LAD through the LIMA into the LSA (panel C). Complete recanalisation of the occluded LSA with subsequent antegrade flow into the LIMA (panel D) was achieved by percutaneous angioplasty and stent implantation (Biotronik, $8 \times 25 \mathrm{~mm}, 14 \mathrm{~atm}$ insufflation pressure) without any complications of cerebral or myocardial ischaemia. His symptoms disappeared and his blood pressure in the left arm was thereafter equal to that in the right arm.

Chest pain only during physical exercise of the left arm in patients with a history of LIMA-to-LAD bypass graft may be pathognomonic for CSSS, representing the clinical correlation of retrograde flow into the LIMA, with resultant coronary ischaemia. Percutaneous transluminal revascularisation by mean of stent implantation is the treatment of choice and can be successfully performed in such cases.

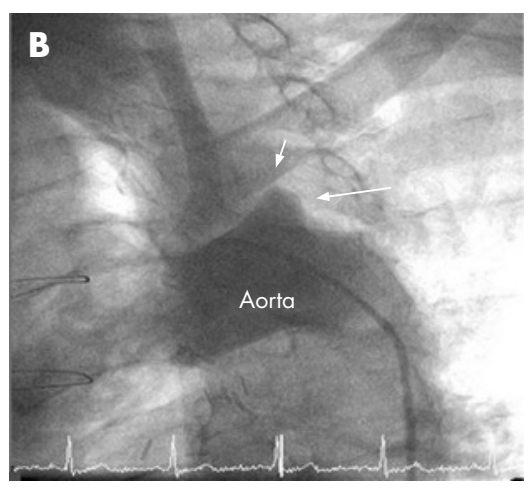

Nasser M Malyar, Christoph Naber, Raimund Erbe nasser.malyar@medizin.uni-essen.de
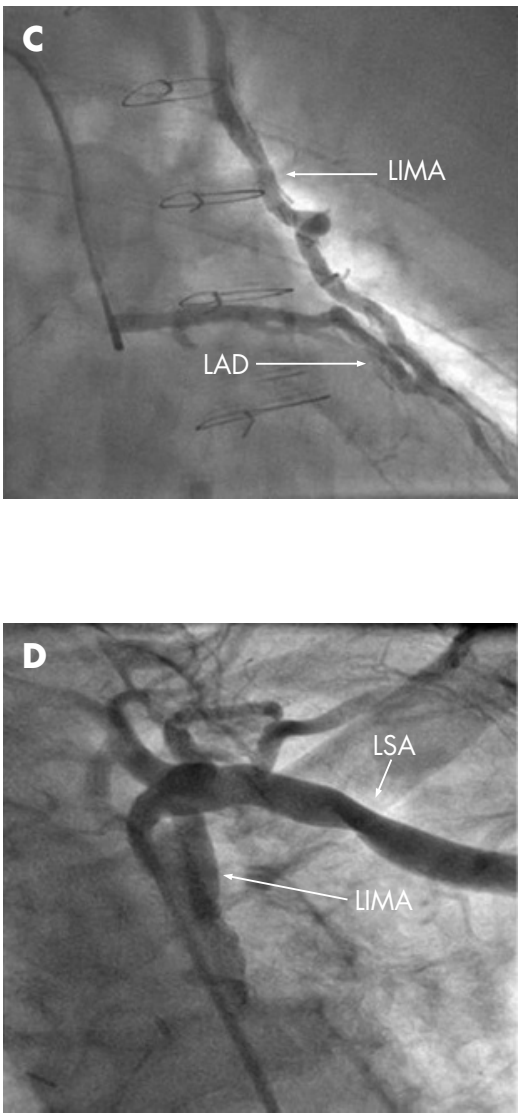